\title{
Integrated Skills and Competence Development through Watching Films in the Target Language
}

\author{
Rita Szaszkó \\ Eszterházy Károly University
}

\section{Introduction}

Films have the potential to inspire and foster diverse emotions including various manifestations of empathy and understanding, and therefore, they are capable of affecting viewers' attitudes, motivations and emotional perceptions. Consequently, carefully selected films can also be regarded as suitable tools to enhance foreign language (FL) learners' diverse skills and competences among which linguistic and intercultural ones are of crucial relevance.

The present paper aims to explore and reveal possible ways of exploiting an English speaking film to develop learners' English language and particularly intercultural competences as wells as their motivations. Also some activities will be presented that can be applied during FL learning processes to enable language learners to experience indirect (non-interpersonal) intercultural contact via watching films in the target language.

Highlighting the ways in which films can be integrated into FL learning processes are relevant due to different factors. First, carefully chosen films in English can be suitable for intercultural educational purposes (Roell, 2010). Second, target language films can greatly enhance students' FL learning motivation to develop their intercultural competences along with their linguistic skills (Pegrum, 2008). Film-based tasks can be grounded on learners' imagination and creativity, which can be regarded as highly motivational factors in FL learning. Since learners have more limited linguistic competence and ability of self-expression in the target language compared to their mother tongue, more careful planning is needed for communicative tasks. Also film-related exercises requiring creativity can reduce the barriers of language learning e.g. language-related anxiety. According to Allwright, Allwright and Bailey (1991), a suitable avenue to explore how to enhance the learning outcomes of FL development in and outside the classroom is to make particular modifications in the teaching process and to observe the results. The changes may comprise integrating culture and art work into teaching and learning and subsequently analysing the benefits and drawbacks of the incorporated new elements in the process. In a similar vein, qualitative classroom research was carried out to gain 
insights into the ways of integrating English speaking films with inter-cultural contents to improve university students' English language skills.

There is a wide selections of films in English which lend themselves for exploitation during English language development classes, in particular because they focus on certain elements of intercultural issues, e.g. empathy, intercultural conflict, racism, stereotypes, ethnic traditions, acculturation/assimilation conflict and the history of the target country (e.g. the UK, the USA). Empathy can be generated towards a member or members of different ethnic, social or cultural group via films, e.g. Bread and Roses (2000), which embellishes the life and problem of a female Mexican working illegally in the USA. A similar theme is presented in the social thriller, Dirty Pretty Things (2002), which depicts the life of two immigrants set in London (Roell, 2010). The Way (Estevez, 2010) is a drama about the Camino de Santiago pilgrimage packed with international pilgrims with different cultural and social background. Intercultural conflict can be illustrated through the true story of A Love Divided (1999), which is about hostility between religions in Ireland, or Save the Last Dance (2001), whose topic is teenage white and black relationship in the USA. Racism is discussed in A Class Divided (1970), which depicts the social-psychological experiment conducted by Jane Elliot after the assassination of Martin Luther King Jr. in 1968. This is England (2006) reveals skinheads in the 1980s. The Prince and Me (2004) shows how people tend to identify stereotypes through the fairy tale love story of an American girl and her fellow Danish student, who turns out to be Crown Prince from Copenhagen (Roell, 2010). Stereotypes also emerge in Green Card (Weir, 1990), which focuses on an American woman and a French man's marriage of convenience to obtain a green card. Ethnic traditions and acculturation/assimilation conflict can be witnessed, e.g. in My Big Fat Greek Wedding (Zwick, 2002) or Blind Dating (Keach, 2006), in which a blind young man falls in love with a young woman of Indian origin, which is a source of difficulty related to different cultural traditions. A part of the history of the target country is highlighted in The Queen about an episode of the life of Queen Elizabeth II (Frears, 2006), The King's Speech about George VI's becoming the monarch of the UK (Hooper, 2010), The Iron Lady (2011) about the late years of Margaret Thatcher or e.g. Forrest Gump (Zemeckis, 1994) unfolds the life of a slow-witted but kind-hearted prodigious man, Gump, who occasionally interferes in some of the defining events of the USA in the second half of the 20th century. Thus, it can be claimed that the repertoire of English speaking intercultural films is huge. Also research suggests that films have much to offer language teachers in helping students to improve their knowledge of language and cultural awareness and sensitivity. There are diverse methodologies, 
techniques and tasks that can significantly motivate and inspire both educators and pupils through the medium of films. Some key elements of films in FL improvement to be focused on are creative technologies, the dimensions of sound, image and time (e.g. flashback - past tenses, narration - present tenses, flashforward - future tenses) ${ }^{1}$, language (including subtitles) and paralanguage. Along with linguistic development in FL teaching and learning processes the European Commission $(2016)^{2}$ also places emphasis among the key competences on multilingual competence, cultural awareness and expression involving creativity as a transversal skill. Consequently, a pilot study was conducted in order to gain insights into the hows of integrating skills and competence development via watching a film in English.

\section{The pilot study}

Aim, rationale and research questions

A small-scale classroom investigation was conducted in order to explore how FL skills development can be executed via various types of methods and techniques based on the utilisation of imagination and creativity and activities related to English speaking films. The study was carried out during an English language development and practice course for students $(\mathrm{N}=12)$ aged 19-22 specialising in teaching EFL in forms 1-6 at primary-school. Research focus on the exploitation of English speaking films in English classes can be considered a pertinent issue since watching films is a popular wide-spread leisure time activity among young adults. According to a representative survey among 15-29-year-old Hungarian youngsters $(\mathrm{N}=8000)$, for this particular age-range the primary spare time activity is film-watching as $77 \%$ of them at weekends while $72 \%$ of them on weekdays spend their recreation time with films ${ }^{3}$. Furthermore, via English-speaking films authentic target language input is ensured (Rixon, 1986) and not only learners' FL skills and intercultural competences can be developed but also the visual input of the film can contribute to better listening comprehension (Markham, Peter and McCarthy, 2008; Tomalin, 1986). Films related to issues of English speaking countries, cultures and people are seen as particularly suitable and essential for students specialising in teaching English at primary school. There are various types of exercises

\footnotetext{
1 https://www.futurelearn.com/courses/short-film-language-teaching

2 https://ec.europa.eu/education/policy/school/competences_en

3 http://www.ujnemzedek.hu/sites/default/files/magyar_ifjusag_2016_a4_web.pdf
} 
on interculture-related films available in diverse categories e.g. immigration, prejudice, culture shock, assimilation, outline of culture, cultural identity etc. (Fox, 2011). However, it must be mentioned that along with the various benefits there are also certain drawbacks of watching films in the target language. On the positive side, there is the possibility of autonomous language learning (e.g. individual learning speed, individual film choice) as well as the efficient improvement of listening comprehension skills. At the same time on the negative side, it must be seen that learning a FL through films is not characterised by a proper focus and a well-designed structure of the language learning process, and there is a total lack of interactive interpersonal communication. Despite the drawbacks a pedagogically carefully-planned film-watching activity including various related tasks can offer numerous advantages in successful language development (Miller, 2016). Accordingly, the present classroom research was created in order to investigate the diverse modes of the advantages and the following research questions were formulated:

1) How can different FL teaching methods be applied for a selected film's pilot activities to activate students' creativity and imagination?

2) How can the pilot exercises improve intercultural competence?

3) How do the pilot tasks affect the students' intrinsic motivation?

As the present small-scale classroom research project has distinctly a qualitative nature, no hypotheses were formulated along with the research questions. Furthermore, the presented results are based on the researcher's notes.

\section{The selection of the film}

The criteria of selecting a film that is suitable for educational purposes consists of several factors. First, it is essential that the film can enhance the students' intrinsic motivation and foster critical thinking (Magnussen, Ishida \& Itano, 2000). Intrinsic motivation can emerge in various ways (Ryan and Deci, 2000) as it can emerge to acquire knowledge and is comprised by the joy of learning and understanding, the discovery of the environment and curiosity for exploration and cognition. Furthermore, another type of intrinsic motivation is the drive for creativity, constitution and development, which are intertwined with the elements of challenge and the sense of efficacy through which the process itself is emphasised. Finally, intrinsic motivation to perceive experiences is identified. Along with the motivation factor another crucial element of film selection is the age factor of the target population. That is, taking into consider- 
ation what topics can draw the target students' attention, which themes can be relevant for the learners regarding their learning and development and which fit into the course schedule and contents, which are compatible with the educational objectives are core criteria. It is crucial that the avoidance of violence for its own sake in films is wise. Also in order to develop FL skills the selection of the proper level of language input level is vital. According to Krashen's input hypothesis (1987), merely through a proper amount input, i+1- level texts and language patterns can develop students' FL skills, which means that the input is slightly more advanced than their present level. It is important to note that concerning films and online videos used for educational purposes the general principle is fair use, which means that the general copyright regulations are not so strict. However, proper and precise citation is required (Levy and Siddiqui, 2009).

The present classroom research focused on the 100-minute American film drama, August Rush (Sheridan, 2007) and the related oral and written creative constructing imaginative activities. The film reveals the peculiar meeting of a young Irish guitarist, Louis (Jonathan Rhys-Meyers) and an American cellist girl, Lyla (Keri Russel) in New York City. The bearing of this encounter is August Rush alias Evan Taylor (Freddie Highmore), who grew up as an orphan since her mother was misled and said that he was born dead, and the new-born baby was given to an orphanage while his father did not even know about his existence. The music prodigy escapes from the orphanage and is desperate to find his parents using his unusual talent and following the music of ether that connects the three of them for good. One day a strange man, Wizard (Robin Williams) spots Evan's peculiar musical gift and he supports and names him August Rush and the intrigues and complications continue. This film can be a suitable choice for B1+/B2/C1 (CERF, 2018) level FL development within the framework of English language practice courses. First, the film is about a peculiar love story full of adventures and turning points, which topic and genre is evergreen for the target age-group, therefore the topic of the film in itself supposes motivation for the movie. Furthermore, the film does not contain autotelic violence and viewers' discretion is not advised. There are conclusions to be drawn from the film and pedagogical elements, for example the embellishment of personalities regarding Wizard's character as well as social criticism.

The parallel between August Rush and the social novel Oliver Twist by Charles Dickens can be soon witnessed, in the film there are emerging allusions,

\footnotetext{
4 Common European Framework of Reference for Languages https://rm.coe.int/cefr-companion-vol-
} ume-with-new-descriptors-2018/1680787989 
which is especially interesting for students specialising in English. Through the film we can glimpse moments of life in New York City, for instance from the aspects of a social worker and youths. The language input of the films is quantitatively and qualitatively is appropriate for the comprehensible input criterion formulated by Krashen (1987). It is beneficial that August Rush is available with English subtitles, too. Markham et al. (2008) investigated the impact of native and target language subtitles of a short documentary on B2-level ${ }^{5}$ university students $(\mathrm{N}=169)$ learning Spanish as a FL. The results showed that the English captions group's performance was significantly the highest while the no captions group's was the lowest. Finally, August Rush fit into the course schedule and it was useful that the participant students had not seen this film before and it is full of melodic rock and classical music.

\section{Film related-tasks, results and discussion}

From a chronological order the tasks based on the film August Rush can be divided into three groups: 1) activities implemented in the lesson prior to and during watching the film, 2) exercises outside the classroom during and consequent to watching the film, and 3) activities in the lesson and outside the lesson after watching the film and doing the related homework. The exercises were designed and carried out by the researcher in two 90-minutes sessions with a special focus on Communicative Language Teaching (CLT), Suggestopedia (Lozanov, 1978), and the Silent Way (SW) first developed by Gattegno in 1963 (Gattegno, 2011). In what follows, some of the most fundamental findings will be discussed along with the pilot exercises.

In the lead-in stage the students with their eyes closed listen to the Rhapsody (Mancina, 2007) composed by Evan/August Rush in the film, during which activity the following questions are asked in the target language while the speech rhythm, the pitch and the intonation are adjusted to the rhythm and dynamics of the music: Which era can this music evoke in you? What kind of scenery and location can you picture? Are there any living creatures? What kinds of feelings and atmosphere can you perceive? What colours can you envision? What scents can you smell? What else can feel? This exercise uses the method of Suggestopedia. Although the music is not Baroque, which is typical of Lozanov's method, it can stimulate the left hemisphere of the brain. The objective of

5 Common European Framework of Reference for Languages https://rm.coe.int/cefr-companion-volume-with-new-descriptors-2018/1680787989 
the task is lead in the students into the atmosphere of the film, to open up their imagination and creative power. The role of imagination and creativity is urgent during the lead-in listening to music stage, when the stimulation of the brain's right hemisphere is taking place in a relaxed and calm atmosphere, which is a typical element of Suggestopedia. Every participant student was able to give an account of his/her inner cinema experience. There were dancing scenes, genre pictures from the turn of the $20^{\text {th }}$ century, a walk in the forest etc. The most challenging task was to recall scents and there were students who were unable to activate this sense of theirs. The music association activity worked with more introvert students as well, however, communication problems occasionally occurred due to lack of proper vocabulary.

The word association exercise was inspired by the SW and can be carried out with using word-cards in group work. On the cards there are cue words pinpointed form the film, e.g. prodigy, orphanage, rhapsody, wizard, August Rush etc. The teacher retires into the background and monitors while listening to how the students define the words and how they connect them to the music they have just heard. Subsequently, there is a similar association activity with some key pictures (Picture 1-2) taken out of the film.

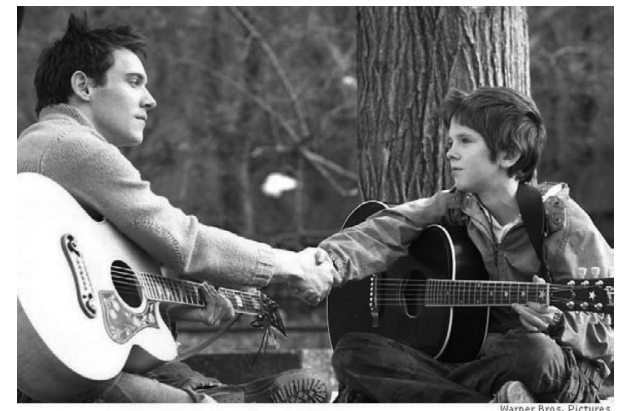

Picture 1

Evan and Louis's first encounter in August Rush (Sheridan, 2007)

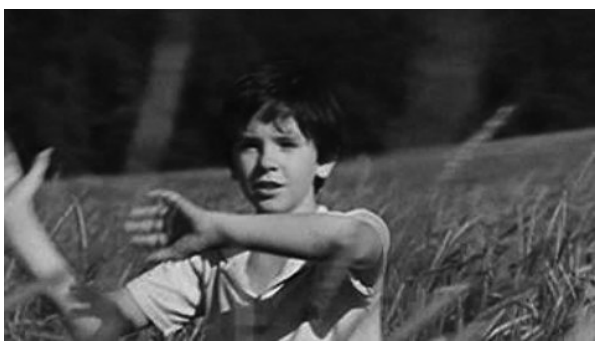

Picture 2

Evan's listening to the music of ether in August Rush (Sheridan, 2007) 
Eventually the groups comprise (in writing or orally) the outline of the story/plot conjured by them. Next, the group discusses in English and organises how to watch the film individually at home. This activity also contributes to the evolution/formation of a cooperative work process. During the word association cards and picture exercise the students' ideas influenced one another and a typical emerging pattern was that there was a character, a musical or Maths prodigy growing up in an orphanage. Furthermore, some learners conjured up August Rush as a settlement or a mountain name instead of being the featuring character child, Evan's nickname. This exercise can be related to the SW, in that the teacher remains silent as much as possible and instead of using Cuisenaire rods, association cards and pictures are applied as aids to elicit students" speech patterns. Also gestures were used during this activity to encourage them to correct their own errors.

The home exercises mainly focuses on the improvement and activation of critical thinking. Every student gets five further word cards, which they have to spot in the film while watching it and they will have to contextualise them in the lesson and give their feedback on the film. A further exercise is to compose a 200-300-word film review about August Rush. Prior to this activity a sample film review of Forrest Gump was focused on in the lesson. The first step is defining and contextualising the home word cards, which is followed by the sharing of personal experience. By using the technique of a new personal identity used in Suggestopedia the students take up the characters imagining and creating a particular character (based on known or invented information) and make an interview with each other. There is also an analysis and evaluation of the activities of the characters via critical thinking including social criticism. Subsequently the task is to elaborate on how the plot could be continued, which activity can be carried out as pair or group work in the lesson or as individual task for home. Finally, an authentic film review can be provided for the students with Student A and Student B handouts with missing information. The use of an information gap exercise based on authentic material is an example of the application of CLT. During the discussion after watching the film at home CLT was applied as the students used the target language in a real life-like situation; that is they expressed their opinion. Also the information gap exercise using an authentic film review as realia (Student A and B film review handout) were distinct tools of CLT to generate discussion in the target language in a natural way. Next, the students made interviews using their new selves as interviewers, August Rush, his parents, Lyla and Louis, Wizard, the Fagin-like figure and Mr. Jeffries, a social worker responsible for Evan. This Suggestopedian new identity exercise proved to reduce language-related anxiety as even extrovert 
students more intensively contributed to the creative word association and film review discussions.

\section{Summary}

Films can be regarded as challenging sources of entertainment, education and a means of extending knowledge. In addition, watching films in the target language is a good ground on which students can develop their several skills and competences. This paper revealed some major findings of a pilot classroom investigation among 12 university teacher trainee students during their English language development course. The objective of the pilot project was to highlight how a film can be integrated into two 90-minute lessons to improve the learners' English as wells as their intercultural competence, critical thinking, intrinsic motivation using the language teaching method of CTL, Suggestopedia and the SW. The research questions and the related answers are as follows.

How can different FL teaching methods be applied for a selected film's pilot activities to activate students' creativity and imagination?

It can be claimed that all the selected three FL teaching methods, that is CLT, Suggestopedia and the SW are suitable to contribute to the stimulation of the participant students' imaginative power. The SW proved to be efficient with association activities which focused on selected music, words/expressions and pictures form the film as wells as with the teacher's silence and correction and self-correction with gestures during these exercise. Suggestopedia exploited the soundtrack of the film as well as the students' new identity in the classroom contributed to a relaxed atmosphere. CLT enhanced active oral and written speech production through authentic materials, real-life-like situations and information gap exercises

How can the pilot exercises improve intercultural competence?

Via in class oral discussions and the film review writing tasks the students had the possibility to improve their intercultural awareness by focusing and talking about cultural stereotypes, ethnic-related issues as well as social criticism. A wide scale of further exercises are essential to make intercultural competence development deeper.

How do the pilot tasks affect the students 'intrinsic motivation?

There were visible sign of the emotional influence of the film on the students' faces, and they also expressed their emotional involvement during the classroom discussions as wells as the informal after-class discussions about the film. It can be concluded that this emotional impact can be related to in partic- 
ular the topic, the plot, the characters, the actors and the music. As a result, the participants searched for further information about the film, the soundtrack and the creators as well.

Due to the small-scale, pilot nature of this study no generalisations can be drawn from the discussed results, which are merely to be seen as descriptive. It is a flaw of the study that due to the 90-minute time constraint only three FL teaching methods were involved. Furthermore, more challenging, less traditional activities can be designed in particular with the application of digital devices and online platforms suitable for educational purposes. As a follow-up exercise students semi-structured interviews can be conducted to elicit the participant students' perceptions and feedback on the film-related session. Also as the continuation of the present research more FL teaching methods can be involved, e.g. Total Physical Response and the Audio-Lingual Method and upto-date digital-based tasks can be designed and online platforms can be included, for instance Edmodo. It is essential to pay a special attention to how the film-related exercises can be adapted to different language learner audiences and level of English knowledge.

In sum, the presented small-scale classroom research suggests that the August Rush project raised the participant students' interest and motivation, enhanced their cooperation and intercultural awareness.

\section{References}

Allwright, D., Allwright, R., \& Bailey, K. M. (1991): Focus on the Language Classroom: An Introduction to Classroom Research for Language Teachers. Cambridge University Press, Cambridge.

Council of Europe (2018): Common European Framework of Reference for Languages: Learning, Teaching, Assessment Companion Volume With New Descriptors. Retrieved from https://rm.coe.int/cefr-companion-volume-with-new-descriptors-2018/1680787989

Estevez, E. (2010): The Way. Film drama. Icon Entertainment International: The United Stated, Spain.

European Commission, Education and Training (2016): Key competences. Retrieved from https://ec.europa.eu/education/policy/school/competences_en

Fox, H. (2011): Intercultural Films that Teachers Can Use. 1 September. Retrieved from https://foxhugh.com/2011/09/01/intercultural-films-that-teachers-can-use/ 
Frears, S. (2006): The Queen. Drama film. Granada Productions: United Kingdom, France, Italy.

Future Learn. Short Film in Language Teaching. Online Course. Retrieved from https://www.futurelearn.com/courses/short-film-language-teaching

Gattegno, C. (2011): The Silent Way. Teaching Foreign Languages in School. Educational Solutions Worldwide Inc.: New York.

Hooper, T. (2010): The King's Speech. Historical drama film. UK Film Council See-Saw Films Bedlam Productions: United Kingdom.

Keach, J. (2006): Blind Dating. Romantic comedy film. Samuel Goldwyn Films LLC: The United States.

Krashen, S. D. (1987): Principles and Practice in Second Language Acquisition. Internet Edition. Retrieved from http://www.sdkrashen.com/content/ books/principles and practice.pdf

Levy, M., \& Siddiqui, S. (2009): What's legal YouTube: Fair use vs. copyright laws.

Videomaker. Retrieved from http://www.videomaker.com/article/c2/14261whats-legal-youtube-fair-use-vs-copyright-laws.

Lloyd, P. (2011): The Iron Lady. Biographical drama film. Pathé Film4 Productions UK Film Council: United Kingdom, France.

Lozanov, G. (1978): Suggestology and Suggestopedia - Theory and Practice. United Nations Educational, Scientific and Cultural Organization. Retrieved on 21 February, 2018 from http://unesdoc.unesco.org/images/0003/000300/030087eb.pdf

Magnussen, L., Ishida, C., \& Itano, J. (2000): The impact of the use of inquiry-based learning as a teaching methodology on the development of critical thinking. Journal of Nursing Education, 39(8), 360-365.

https://doi.org/10.3928/0148-4834-20001101-07

Markham, P. L., Peter, L. A., \& McCarthy, T. J. (2008): The Effects of Native Language vs. Target Language Captions on Foreign Language Students' DVD Video Comprehension. Foreign Language Annals, 31 December.

Miller, E. (2016): Can you learn a new language by watching movies? Strategies in Language Learning. Retrieved from http://www.strategiesinlanguagelearning.com/learn-new-language-by-watching-movies/

Pegrum, M. (2008): Film, Culture and Identity: Critical Intercultural Literacies for the Language Classroom, Language and Intercultural Communication, 8(2), 136-154.

https://doi.org/10.1080/14708470802271073

Rixon, S. (1986): Developing listening skills. McMillan Publishers Limited, London. 
Roell, C. (2010): Intercultural Training with Films. English Teaching Forum. 2 November. Retrieved 2018 from https://americanenglish.state.gov/files/ae/ resource_files/48_2-etf-intercultural-training-with-films.pdf

Ryan, R.M., \& Deci, E. L. (2000): Self-Determination Theory and the Facilitation of Intrinsic Motivation, Social Development, and Well-Being. American Psychologist, 55(1), 68-78.

https://doi.org/10.1037/0003-066X.55.1.68

Sheridan, K. (2007): August Rush. Southpaw Entertainment, CJ Entertainment: United States.

Tomalin, B. (1986): Video, TV \& radio in the English class. Macmillan Publishers Limited, London.

Weir, P. (1990): Green Card. Comedy film. Touchstone Pictures Umbrella Entertainment: United States, Australia, France.

Zemeckis, R. (1994): Forrest Gump. Romantic drama film. Paramount Pictures: United States.

Zwick, J. (2002). My Big Fat Greek Wedding: Romantic comedy film. Gold Circle Films

HBO Films MPH Entertainment Playtone: Canada, United States.

\begin{abstract}
Precisely selected films in the target language lend themselves to developing foreign language learners' various skills and competences, in particular their linguistic, social, psychological and intercultural ones in an integrated way (Pegrum, 2008). Various exercises, which are based on the imagination and creativity of foreign language learners, can be attached to films. Fantasy and creativity can facilitate learners to reduce their language-related anxiety and also they are fundamental factors of enhancing language learning motivation and attitudes. The goal of this presentation is to reveal the findings of a smallscale study on students' perceptions regarding using films and different related tasks in their foreign language development lessons.
\end{abstract}

